\title{
BMJ Open Hospital Survey on Patient Safety Culture: psychometric evaluation in Kuwaiti public healthcare settings
}

\author{
Gheed Al Salem, ${ }^{01,2}$ Paul Bowie, ${ }^{3}$ Jill Morrison ${ }^{4}$
}

To cite: Al Salem G, Bowie P, Morrison J. Hospital Survey on Patient Safety Culture: psychometric evaluation in Kuwaiti public healthcare settings. BMJ Open 2019:9:e028666. doi:10.1136/ bmjopen-2018-028666

- Prepublication history and additional material for this paper are available online. To view please visit the journal online (http://dx.doi.org/10.1136/ bmjopen-2018-028666).

Received 18 December 2018 Revised 8 April 2019 Accepted 9 April 2019
Check for updates

(C) Author(s) (or their employer(s)) 2019. Re-use permitted under CC BY-NC. No commercial re-use. See rights and permissions. Published by BMJ.

${ }^{1}$ Institute of Health and Wellbeing, University of Glasgow, Glasgow, UK

${ }^{2}$ Quality and Accreditation Directorate, Ministry of health, Kuwait City, Kuwait

${ }^{3}$ Safety \& Improvement, NHS Education for Scotland, Glasgow, Scotland, UK

${ }^{4}$ General Practice and Primary Care, University of Glasgow, Glasgow, UK

Correspondence to

Dr Gheed Al Salem;

drgheed@aol.com

\section{ABSTRACT}

Objective As healthcare organisations endeavour to improve the quality and safety of their services, there is increasing recognition of the importance of building a culture of safety to promote patient safety and improve the outcomes of patient care. Surveys of safety culture/climate have not knowingly been conducted in Kuwait public hospitals, nor are valid or reliable survey instruments available for this context. This study aims to investigate the psychometric properties of the HSOPSC (Hospital Survey on Patient Safety Culture) tool in Kuwaiti public hospitals in addition to constructing an optimal model to assess the level of safety climate in this setting.

Design Cross-sectional study.

Setting Three public hospitals in Kuwait.

Participants About 1317 healthcare professionals.

Main outcome measure An adapted and contextualised version of HSOPSC was used to conduct psychometric evaluation including exploratory factor analysis, confirmatory factor analysis reliability and correlation analysis.

Results 1317 questionnaires (87\%) were returned. Psychometric evaluation, showed an optimal model of eight factors and 22 safety climate items. All items have strong factor loadings (0.42-0.86) and are theoretically related. Reliability analysis showed satisfactory results $(\alpha$ $>0.60$ ).

Conclusions This is the first validation study of a standardised safety climate measure in a Kuwaiti healthcare setting. An optimal model for assessing patient safety climate was produced that mirrors other international studies and which can be used for measuring the prevailing safety climate. More importance should be attached to the psychometric fidelity of safety climate questionnaires before extending their use in other healthcare culture and contexts internationally.

\section{INTRODUCTION}

Modern healthcare systems are concerned with improving the safety of patient care and attempting to build strong organisational safety cultures. 'Safety Culture' is identified as a key element of a healthcare organisation's ability to learn openly from safety incidents and reduce preventable harm to patients. The perceived importance of safety culture in improving patient safety and its impact

\section{Strengths and limitations of this study}

A rigorous and scientific psychometric approach was designed and executed based on recommended reporting practices to test the original Hospital Survey of Patient Safety Culture (HSOPSC) model and construct an optimal model.

- The large sample size $(n=1280)$ allowed for the data set to be split and for factor analysis to be undertaken with acceptable model fit indices.

- One limitation is the number of items per factor in the optimal model. Three factors contained only two items per factor in the final eight-factor model.

- Another limitation is the exclusion of partially answered questionnaires. As a result, a subset of the total sample, with all items answered, was used for validation of the psychometric properties of HSOPSC.

on clinical outcomes has led to a growing interest in the assessment of safety culture in healthcare organisations. The use of survey questionnaires is one of the most popular methods for assessing safety culture. These surveys aim to measure healthcare workers' perceptions of the prevailing safety culture or 'safety climate' in their organisations.

There are numerous definitions of safety culture and safety climate. Despite their distinctive terminologies, they are commonly used arbitrarily and interchangeably in the literature. ${ }^{1}$ Safety culture has been described as a set of shared values, beliefs, norms and attitudes that interact with an organisation's structure and control systems resulting in behavioural norms. ${ }^{23}$ Safety climate provides a 'snapshot' of the perceptions held by healthcare workers about visible, surface-level features of safety culture at a given point in time. ${ }^{4}$ It 'assesses workforce perceptions of procedures and behaviours in their work environment that indicate the priority given to safety relative to other organisational goals, ${ }^{5}$

Assessing the status of the existing safety climate in a healthcare organisation is promoted as the first step for developing a strong and solid safety culture. ${ }^{6}$ The resulting 
data potentially offer policymakers, healthcare providers, teams and managers a clear view of areas in need of attention to strengthen the prevailing safety climate, in addition to identifying specific challenges that impede progress in safety initiatives. ${ }^{7}$ It can also be used for benchmarking and improving safety climate measures across time and between organisations on national and international levels. $^{89}$

A range of safety climate assessment tools have been developed for acute hospital settings, although the scientific rigour with which they were designed and tested is variable. ${ }^{51011}$

Multiple reviews of patient safety climate instruments have been published. ${ }^{510-16}$ Most concluded that the Safety Attitudes Questionnaire and the Hospital Survey on Patient Safety Culture (HSOPSC) were the most appropriate tools available in terms of their psychometric properties, and critiqued climate tools generally as many lack appropriate scale development, validation and evidence for their predictive validity. Over a decade ago, Flin $e t a \tilde{l}$ argued that it is essential that tools are developed with robust psychometric properties to enable valid interpretations of patient safety climate test scores to be made.

Despite this, many published studies are still limited in their reporting of the necessary psychometric properties of questionnaires. ${ }^{510} 1718 \mathrm{It}$ is argued that HSOPSC is one of the most rigorously tested instruments with good psychometric properties in addition to being tested on the necessary large sample sizes. ${ }^{5}$ Psychometric analysis involves the use of established statistical assessment techniques to assess the psychometric properties of questionnaires and identify the underlying safety culture dimensions. ${ }^{11}$

Repeated high-profile media coverage has drawn the attention of Kuwaiti politicians and the public to failings in healthcare delivery and patient safety, which has contributed to growing demands for a better quality of care. ${ }^{19-21}$ Subsequent inquiries and reports have placed patient safety high on the policy agenda of Kuwait. The Ministry of Health (MOH) responded by investing significantly in the improvement of healthcare services. Safety climate assessment is one of the latest approaches to be adopted by the $\mathrm{MOH}$ with the goal of evaluating and improving patient safety in Kuwaiti hospitals.

Surveys of safety climate have yet to be conducted at public hospitals in the state of Kuwait, nor are valid or reliable survey instruments available for this purpose. This study aims, therefore, to assess the psychometric properties of the HSOPSC tool in Kuwaiti public hospitals in addition to constructing an optimal model to assess the level of safety climate in this setting and to benchmark the data against other international studies.

\section{METHOD}

\section{Instrument selection}

HSOPSC is a 12-factor, 42-item survey questionnaire. It assesses 10 climate dimensions of patient safety, with two outcome measures (overall perceptions of patient safety and frequency of event reporting). Two additional singleitem outcome measures are included.$^{22} 23$ The HSOPSC tool was chosen for this study for several reasons. First, a systematic review of tools designed for acute hospital settings concluded that HSOPSC had good overall methodological quality with good assessment of the tool's reported psychometric properties. ${ }^{24}$ Second, HSOPSC was one of the most rigorously tested instruments at the time of selection, with extensive literature reporting its psychometric properties. ${ }^{5}$ The tool has been extensively used in hospitals in USA where it was originally developed, ${ }^{25}$ and validated for use in more than 60 countries and translated into 30 different languages. ${ }^{26-33}$ Thirdly, HSOPSC is a comprehensive measure of safety climate as it assesses key aspects related to patient safety at multiple levels of analysis including the individual, unit and hospital levels (table 1). Finally, the tool is freely available, and uses clear language with a scale that is simple and easy to follow.

\section{Instrument modification}

The English version of the tool was pilot tested and modified for Kuwaiti healthcare in order to solve any technical and feasibility issues associated with its application. ${ }^{34} 35$ Seven face-to-face interviews were conducted with a panel of healthcare staff from $\mathrm{MOH}$ (including doctors, nurses and risk and safety officers) to evaluate HSOPSC content and ensure the proper transfer of the intended meaning of the questionnaire items to the culture and language differences in the Kuwaiti context. The panel endorsed the HSOPSC content as being of high relevance to safety culture in Kuwaiti hospitals. All items were retained. However, wording was modified in eight items to clarify their meaning as some comments indicated potential ambiguity in items' interpretations.

\section{Instrument testing}

A stratified random sample was drawn from healthcare clinical staff in three public hospitals in Kuwait. To ensure that the sample size was adequate to satisfactorily undertake factor analysis (FA), sample size requirements (sample size of the study, ratio of the sample size to the number of variables, ratio of the number of variables to the number of factors) were evaluated. ${ }^{36}$ The Tabachnick and Fidell ${ }^{37}$ rule recommends having at least 300 cases to undertake FA. The Kaiser-Meyer-Olkin (KMO) coefficient was used as another measure of sampling adequacy. KMO coefficient values range between 0 and 1 . Surveys of health professionals can be challenging and are characterised by declining response rates $^{38}$ with a significant downward trend in response rates from 1998 to $2008 .^{39}$ Based on their findings, the predicted response rate for this study was $20 \%$ and it was estimated that the sample size should be a minimum of 1500 of distributed questionnaires.

\section{Data collection and management}

Staff members were invited by letter to participate in the study. Questionnaires were distributed across different 
Table 1 HSOPSC patient safety culture dimensions and definitions ${ }^{40}$

\section{Patient safety culture composite}

Communication openness

\section{Definition: The extent to which...}

Staff freely speak up if they see something that may negatively affect a patient and feel free to question those with more authority.

Feedback and communication about Staff are informed about errors that happen, are given feedback about changes error

Frequency of events reported implemented and discuss ways to prevent errors.

Mistakes of the following types are reported: (1) Mistakes caught and corrected before affecting the patient. (2) Mistakes with no potential to harm the patient. (3) Mistakes that could harm the patient but do not.

Handoffs and transitions Important patient care information is transferred across hospital units and during shift changes.

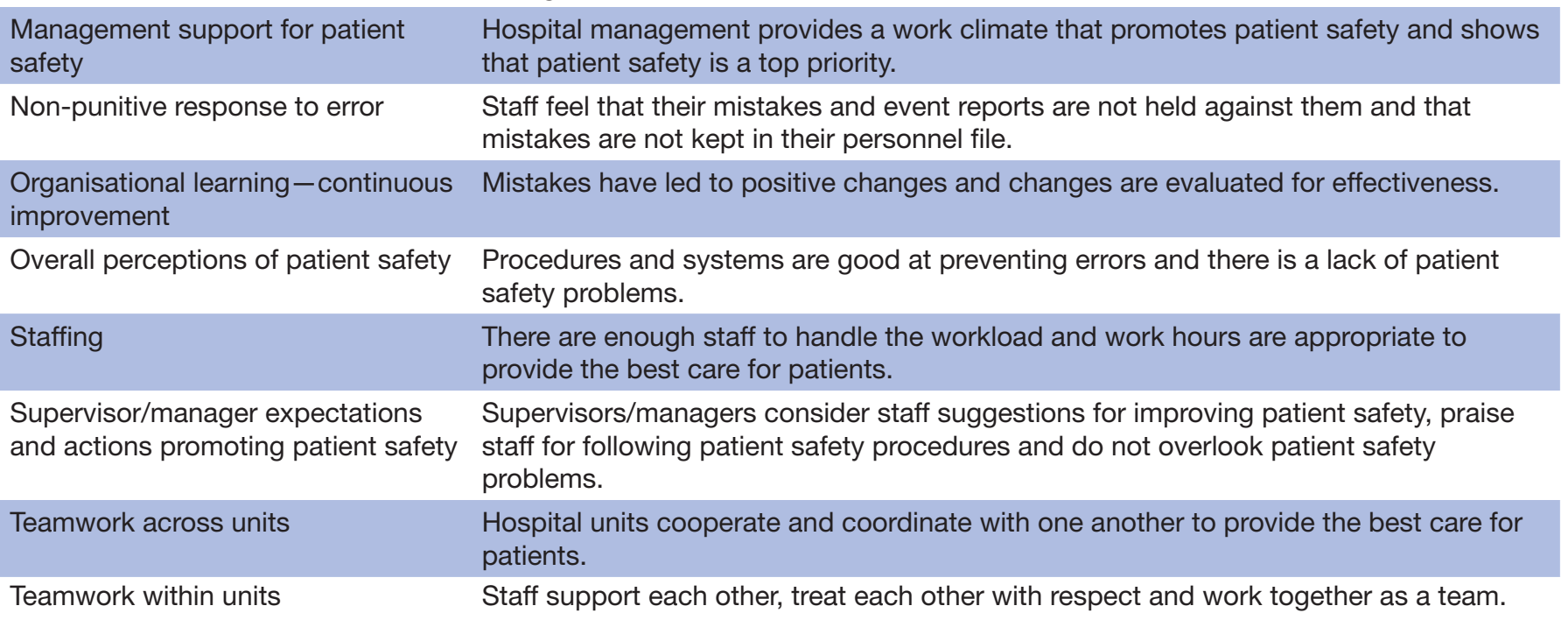

HSOPSC, Hospital Survey on Patient Safety Culture.

departments in the three public hospitals. The questionnaires were completed anonymously and returned to multiple collection boxes located within the hospitals. Data were coded and entered into an electronic data file using the Statistical Package for Social Sciences (SPSS V.24). Negatively worded items were reverse coded. If less than one entire section of the survey was answered or less than half of the items throughout the entire survey (in different sections) were answered, or if every item was answered the same, these questionnaires were excluded. ${ }^{40}$ Missing values were deleted in a listwise manner in order to minimise any possible biases. ${ }^{41}$

\section{Factor analysis}

FA is a statistical method that 'explores the extent to which individual items in a questionnaire can be grouped together according to the correlations between the responses to them', thus reducing the dimensionality of the data. ${ }^{42}$ It can be applied as a data reduction or a structure detection method. ${ }^{43}$ The two main techniques of FA are exploratory factor analysis (EFA), and confirmatory factor analysis (CFA), which are both recommended to test construct validity. ${ }^{44}$

EFA allows the researcher to uncover the main dimensions to develop a theory or model from a smaller number of latent constructs that are often represented by a larger set of measured variables. ${ }^{45} 46$ CFA tests a predetermined factor structure or a proposed theory. ${ }^{45}$ This study combined both approaches to develop an optimal model, based on the original HSOPSC model, for specifically assessing patient safety climate in Kuwaiti public hospitals. Due to the controversy associated with conducting EFA and CFA on the same data, a split-half validation technique is recommended. ${ }^{48}$ Therefore, the Kuwaiti data set was randomly split into two independent data sets using SPSS V.24. Each group contains a set of $640(n=640)$ cases-the calibration half of the data set was used for model construction and the validation half of the data set was used for confirming the explored factor structure resulting from model construction.

Data analysis was based on three main phases. (1) To investigate whether the original HSOPSC 12- factor model is appropriate for the Kuwaiti data. Both CFA and reliability analysis were used at this step. (2) To examine whether an alternative factor model would fit the Kuwaiti data better. For model construction, EFA was carried out using the calibration half of the data set (sample A, n=640). (3) Undertaking CFA and reliability analysis using the validation half of the data set, to test the fit of the resultant model from the previous phase (sample B, $\mathrm{n}=640)$. Cronbach's $\alpha$ was calculated for each factor to examine the internal consistency or reliability with the 
minimum criterion for acceptable reliability of at least $\alpha \geq 0.60$ as recommended for the majority of research purposes. ${ }^{49}{ }^{50}$ Factor correlations of the optimal model were performed in addition to comparisons between the CFA output of our optimal factor model and the outputs reported in previous studies.

\section{Patient and public involvement statement}

Patient and public were not involved in the design, planning or the analysis of the study.

\section{RESULTS}

\section{Response rate and sample demographics}

Of the 1511 questionnaires distributed at the three hospitals, 1317 questionnaires (87\%) were returned. A KMO statistic of 0.88 was calculated, which indicates that the sample has a sufficient level of homogeneity. ${ }^{51}{ }^{52}$ Thirty-seven questionnaires were excluded. Online supplementary appendix 1 summarises the relevant demographics of survey respondents.

\section{Instrument testing}

Following the deletion of missing values, 1280 were considered eligible and this number of completed questionnaires $(n=1280)$ was sufficient to undertake FA.

\section{Testing the original HSOPSC (12-factor) model}

A CFA was performed, using AMOS software,${ }^{53}$ to test the model fit of the original HSOPSC 12-factor structure using Kuwaiti data $(n=1280)$. The global fit of our model was not consistently satisfactory for the Kuwaiti data. Values indicate that the fit is not acceptable to confirm the proposed factor structure as the three criteria measures including CFI (CFI values $\geq 0.90),{ }^{54} \mathrm{X}^{2} / \mathrm{DF}\left(\mathrm{X}^{2} / \mathrm{DF} \leq 2\right)^{55}$ and Tucker-Lewis Index (TLI) (TLI of $>0.90)^{54}$ did not fit the values that indicate a good model fit.

The internal consistency of the Kuwaiti data $(n=1280)$ was $\geq 0.60$ within nine dimensions. Three dimensions had internal consistencies less than 0.60. Additionally, two dimensions have a questionable internal consistency because their Cronbach's $\alpha$ value was 0.60 (Cronbach's $\alpha=0.604$ for 'Non-punitive Response to Errors' and Cronbach's $\alpha=0.601$ for 'communication openness'). In summary, the results of the CFA and reliability analysis indicate that the original HSOPSC 12-factor model is not a satisfactory fit when it is used for Kuwaiti data. Therefore, an EFA was used for investigating an alternative factor structure which might be more appropriate for Kuwaiti data.

\section{Construction of an optimal model}

EFA consists of two basic stages: (1) Estimating the number of factors that should be extracted to represent the HSOPSC factor structure. (2) Interpreting the meaning of the extracted factors and representing them in terms of theoretical structures that reflect the patient safety climate dimensions. EFA (principal axis factoring with varimax then oblique rotation) was performed

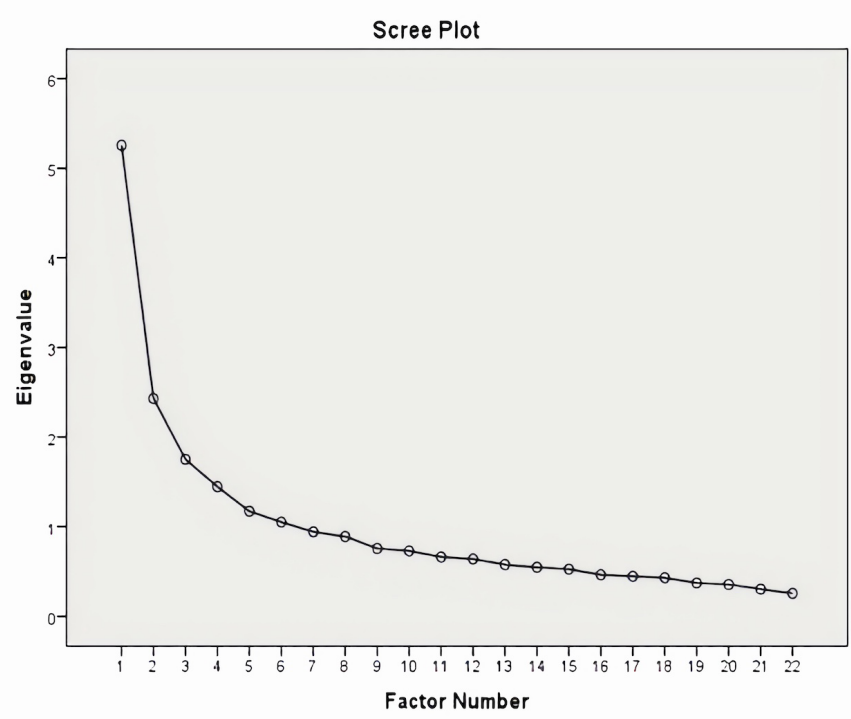

Figure 1 Scree plot of the final EFA solution (eight factors, 22 items).

on the calibration half of the data set $(n=640)$. Based on the Kaiser criterion of eigenvalues $>1^{51}$ and Cattell scree plot, ${ }^{56}$ different numbers of factors $(12,11,10,9$, 8,7 factors) were extracted and investigated to find the optimal alternative model (see online supplementary appendix 2).

Following the rotation of factors the factor pattern matrix was examined to decide on the acceptable level of loading for variables to define factors. ${ }^{57}$ To reach a satisfactory solution, a number of points need to be taken into consideration including identifying items with low communalities $(<0.3)$, no or low loading $(<0.4)$, items with cross loadings $(>0.30)$ and the theoretical structure of items. It should be noted that the decision on how many factors to retain is based on the degree of comprehensibility and interpretability of the factor structure in the context of the research. ${ }^{58}$ In addition, theoretical knowledge regarding the construct under study is more significant than a statistical measure and the items and factors should make conceptual sense and be theoretically related. ${ }^{57}$

\section{Final factor solution}

An eight-factor solution (all loadings $\geq 0.40$ ) showed the best model fit to the Kuwaiti data set. The Scree plot of the final EFA solution is shown in figure 1. The structure and factor loadings of the final EFA solution are reported in table 2 . The final solution explains $50.2 \%$ of variance by eight extracted factors and represents 22 items from the safety climate questionnaire (20 items were excluded). All factor loadings are within the range of $0.428-0.864$.

Five factors (factor 2, factor 3, factor 4, factor 6 and factor 7) have three or more items with loading $>0.4$. Factor 1, factor 5 and factor 8 have two items with very high loading of $>0.5$ and the items in each factor are theoretically related (table 3 ). There are no cross-loaded items and there are no items with loading $<0.4$ and with 
Table 2 Pattern matrix of the final EFA solution (eight factors, 22 items)

\begin{tabular}{|c|c|c|c|c|c|c|c|}
\hline \multirow[b]{2}{*}{ Variable } & \multicolumn{7}{|l|}{ Factor } \\
\hline & 2 & 3 & 4 & 5 & 6 & 7 & 8 \\
\hline $\begin{array}{l}\text { (B1) My supervisor/manager says a good word } \\
\text { when he/she sees a job done according to } \\
\text { established patient safety procedures (SMEA) }\end{array}$ & 0.822 & & & & & & \\
\hline
\end{tabular}

(B2) My supervisor/manager seriously considers 0.623

staff suggestions for improving patient safety

(SMEA)

\section{(E2) When a mistake is made, but has no potential to harm the patient, how often is this reported? (FER)}

(E1) When a mistake is made, but is caught and corrected before affecting the patient, how often is this reported? (FER)

\section{(E3) When a mistake is made that could harm the patient, but does not, how often is this reported? (FER)}

(D5) Important patient care information is often lost during shift changes. (negatively worded) $(\mathrm{HO})$

(D3) Things 'fall between the cracks' when transferring patients from one unit to another (negatively worded) (HO)

(D6) It is often unpleasant to work with staff from other hospital units. (negatively worded)

(TWAU)

(D7) Problems often occur in the exchange of information across hospital units. (negatively worded) $(\mathrm{HO})$

(A16) Staff worry that mistakes they make are kept in their personnel file. (negatively worded) (NRPE)

(A8) Staff feel like their mistakes are held (used) against them. (negatively worded) (NPRE)

(A12) When an incident is reported, it feels like the person is being reported, not the problem. (negatively worded) (NPRE)

(D4) There is good cooperation among hospital units that need to work together (TWAU)

(D2) Hospital units do not coordinate well with each other (negatively worded) (TWAU)

\section{(A1) People support one another in this unit} (TWWU)

(A3) When a lot of work needs to be done quickly, we work together as a team to get the work done (TWWU)

(A4) In this unit, people treat each other with respect (TWWU)

(C6) Staff are afraid to ask questions when

\section{Factor}


Table 2 Continued

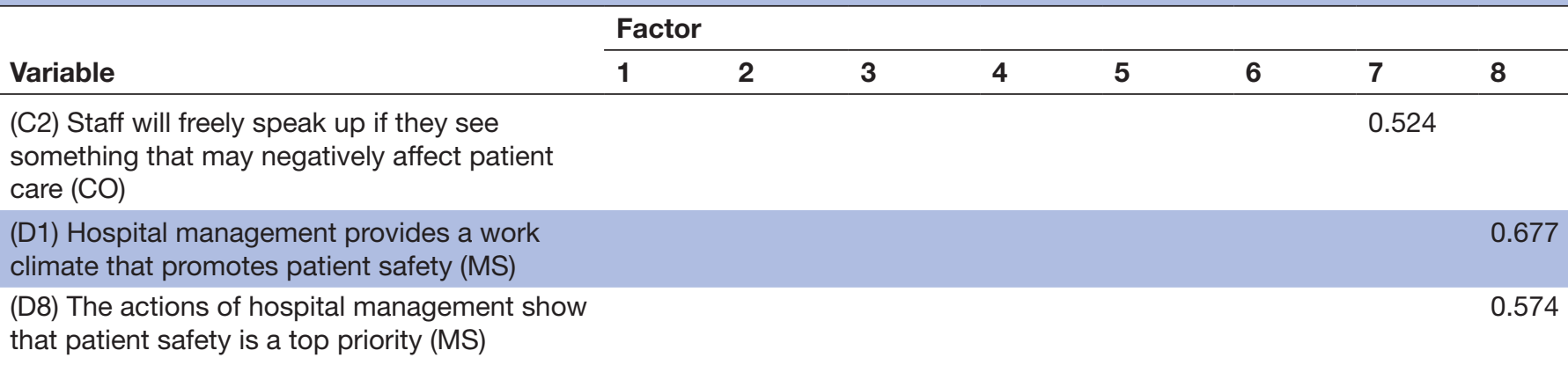

Rotation converged in 16 iterations.

Supervisor/manager expectations and actions promoting safety (SMEA), Non-punitive response to error (NPRE).

Extraction method: principal axis factoring. Rotation method: oblimin with Kaiser normalisation.

$\mathrm{CO}$, communication openness; EFA, exploratory factor analysis; FER, frequency of incident reporting; HO, hospital handoffs and transitions;

MS, hospital management support for patient safety; TWAU, teamwork across hospital units; TWWU, teamwork within hospital units.

communalities $<0.3$ in the solution. The solution is essentially consistent with all items within each factor theoretically related. Only D6 moved from 'Teamwork across units' to 'Handoffs and transitions'.

\section{Testing the final factor (eight-factor) model}

The optimal eight-factor model was vigorously examined by conducting two confirmatory analyses initially using the validation half of the data set $(n=640)$, followed by the whole data set $(n=1280)$. All estimated parameters indicate a good model fit (eight factors and 22 items) as reported in table 4 .

The standardised path coefficients reflecting the strength of the relationship between items and dimensions $^{59}$ were found to be generally large $(>0.50)$ and ranged from 0.46 (communication openness) to 0.89 (frequency of incidents reported) (see online supplementary appendix 3). Therefore, this model was accepted as the optimal model of HSOPSC for the Kuwaiti healthcare setting.

\section{Reliability}

Reliability analysis was performed using the whole sample with Cronbach's $\alpha$ values reported to be $\geq 0.60$ for all factors. Therefore, the internal consistency was acceptable for the eight-factor solution (table 3). In order to test the construct validity of the HSOPSC instrument, intercorrelation coefficients with Pearson's $\boldsymbol{r}$ were calculated between the eight factors in addition to the two single-item outcome measures (patient safety grade and number of incidents reported).

The Pearson's correlation coefficients between scale scores are reported in online supplementary appendix 4.

Intercorrelation coefficients ranged between 0.08 and 0.72. All correlation coefficients are significant. The highest correlations were those between 'Management support for patient safety' and 'Teamwork across units' $(r=0.722)$. All eight factors are interrelated to each other. Most of the correlation coefficients indicate a moderate correlation between dimensions. This indicates that no two factors are measuring the same construct.

\section{Proposed optimal eight-factor model for Kuwaiti data}

As shown in box 1, the proposed optimal model structure includes eight dimensions and 22 items.

\begin{tabular}{|c|c|c|c|c|}
\hline $\begin{array}{l}\text { Number of } \\
\text { factor }\end{array}$ & Factor & $\begin{array}{l}\text { Heavy loaded items } \\
(>0.4)\end{array}$ & $\begin{array}{l}\text { Number of } \\
\text { items }\end{array}$ & Cronbach's $\alpha$ \\
\hline 1 & $\begin{array}{l}\text { Supervisor/manager expectations and } \\
\text { actions promoting safety }\end{array}$ & B1-B2 & 2 & 0.776 \\
\hline 2 & Frequency of events reported & E1-E2-E3 & 3 & 0.858 \\
\hline 3 & Handoffs and transitions & D3-D5-D6-D7 & 4 & 0.685 \\
\hline 4 & Non-punitive response to errors & A8-A12-A16 & 3 & 0.604 \\
\hline 5 & Teamwork across units & D2-D4 & 2 & 0.689 \\
\hline 6 & Teamwork within units & A1-A3-A4 & 3 & 0.705 \\
\hline 7 & Communication openness & $\mathrm{C} 2-\mathrm{C} 4-\mathrm{C} 6$ & 3 & 0.601 \\
\hline 8 & Management support for patient safety & D1-D8 & 2 & 0.724 \\
\hline
\end{tabular}


Table 4 CFA results of the eight-factor optimal model (validation sample and whole sample)

\begin{tabular}{lllllllll}
\hline $\begin{array}{l}\text { Eight-factor } \\
\text { model }\end{array}$ & $\chi^{2}$ statistic $\left(\chi^{2}\right)$ & DF & $\begin{array}{l}\text { CMIN/DF } \\
\left(\chi^{2} / D F\right)\end{array}$ & CFI & RMR & SRMR & RMSEA & TLI \\
\hline Validation sample & 424.9 & 181 & 2.3 & 0.94 & 0.049 & 0.048 & 0.046 \\
& good & good & acceptable & good & good & good & good & good \\
Whole sample & 617.8 & 181 & 3.4 & 0.946 & 0.041 & 0.038 & 0.043 & 0.931 \\
& good & good & acceptable & good & good & good & good & good \\
\hline
\end{tabular}

CFA, confirmatory factor analysis; CFI, Comparative Fit Index; CMIN, Chi-square Mean; DF, degree of freedom; RMR, root mean square residual; RMSEA, root mean square error of approximation; SRMR, standardised root mean square residual; TLI, Tucker-Lewis Index.

\section{DISCUSSION}

This psychometric evaluation is the first reported validation study of a standardised safety climate measure in a Kuwaiti healthcare setting. The psychometric properties of the HSOPSC questionnaire were assessed and an optimal model for assessing patient safety climate in Kuwaiti hospitals was constructed. The final questionnaire contains 22 safety climate items (variables) that measure eight safety climate factors. The optimal model's psychometric properties (including validity and reliability) were good with all items loading strongly $(>0.40)$ onto one factor and all items, within each factor, were theoretically related.

Our results are in line with other studies investigating the psychometric properties of the original HSOPSC questionnaire. The suitability of the original HSOPSC model for Kuwaiti data was tested and results revealed an unsatisfactory fit. ${ }^{60}$ Different international studies ${ }^{28} 326162$ reported similar findings. This finding is in contrast with other studies that assessed patient safety climate by using the original HSOPSC questionnaire ${ }^{60}$ in hospitals without examining the reliability and validity of the questionnaire in a different context. ${ }^{63-69}$

Various underlying factor structures were identified as optimal factor models. The original 12-factor model was replicated in Belgian, ${ }^{6}$ Portuguese ${ }^{70}$ Brazilian $^{71}$ and Scottish data. ${ }^{72}$ Other studies reported 11-factor models for Dutch, ${ }^{31}$ Arabic, $^{62}$ Croatian $^{73}$ and Norwegian data ${ }^{74}$ 10-factor models for French, ${ }^{29}$ Turkish, ${ }^{27}$ Chinese ${ }^{75}$ and Brazilian data; ${ }^{76}$ 9-factor models for $\mathrm{UK}^{32}$ and Slovene data; ${ }^{77} 8$-factor models for Swiss, ${ }^{28}$ Saudi, ${ }^{61}$ Kosovo $^{78}$ and Kuwaiti data. This discrepancy in results could be attributed to differences in employing survey methods and psychometric analytical techniques, in addition to the various modifications made to adapt the original instrument to different healthcare settings. ${ }^{72}$ Neglect of crucial elements, including context, processes and actors involved, when attempting to adapt an instrument in a different setting might lead to conflicting results and might weaken the validity of the instrument. ${ }^{79}$ Thus, the original HSOPSC will clearly be limited when used in other contexts without proper assessment of its psychometric properties.

The optimal model of our study is in line with other international studies. ${ }^{32}{ }^{61}$ Four dimensions were either dropped or merged with other factors into a single dimension. In our study, the same dimensions reported low reliability using the original HSOPSC in addition to other international studies. ${ }^{326180}$ The optimal model was confirmed using CFA with good model fit indices. This was consistent with the CFA results of the optimal models of USA ${ }^{60}$ Saudi Arabia, ${ }^{61}$ Palestine, ${ }^{62}$ UK $^{32}$ and Scotland. ${ }^{72}$

Considering all of this evidence, it seems that the original HSOPSC questionnaire ${ }^{60}$ does not appear to perform well in different countries. Survey instruments that are designed for particular settings are tailored to meet the unique characteristics and contexts of the local setting and population. In the case of HSOPSC, a number of the reported adaptations have performed less well than the original tool. ${ }^{29} 32747581$ This might be due to the contextual specificity of the construct of safety culture. ${ }^{82}$ Other factors include unique country characteristics, types of health systems and settings, staff groups and cultural differences. ${ }^{28} 83$ Hedsköld $e t a l^{79}$ pointed out that such differences might weaken the validity of the instrument.

In a review of quantitative patient safety culture instruments, it was concluded that all of the surveys designed for general administration to hospital personnel addressed three common dimensions: management support and commitment to safety, communication openness and teamwork. ${ }^{11}$ They suggested that these common dimensions might be considered 'core dimensions' of patient safety culture. In addition, a number of dimensions seem to be common among optimal factor models across different countries.

Factor structure of the optimal model of our study compared with optimal models that were developed in Saudi Arabia, Palestine, England, Scotland, the Netherlands, Turkey and Switzerland, in addition to the original US HSOPSC questionnaire, ${ }^{60}$ is shown in online supplementary appendix 5 . This comparison is aimed at identifying a common set of patient safety culture dimensions across different countries.

Six studies reported different dimensions combined into one dimension. A significant degree of overlap in the content of the safety culture dimensions exists. As a result, included items in certain dimensions tend to load onto differently labelled dimensions. 'Feedback and communication about error' and 'Communication openness' were grouped into one dimension in the Palestinian, Swiss and Scottish studies. ${ }^{28} 6280$ This result is expected as both dimensions are closely related. Feedback and communication with staff about errors and discussing ways to prevent them are linked to allowing staff to freely 
Box 1 Proposed eight-factor optimal model for Kuwaiti data

Factor 1: Supervisor/manager expectations and actions promoting patient safety (two items)

- B1: My supervisor/manager says a good word when he/she sees a job done according to established patient safety procedures.

- B2: My supervisor/manager seriously considers staff suggestions for improving patient safety.

Factor 2: Frequency of events reported (three items)

- E1: When a mistake is made, but is caught and corrected before affecting the patient, how often is this reported?

- E2: When a mistake is made, but has no potential to harm the patient, how often is this reported?

- E3: When a mistake is made that could harm the patient, but does not, how often is this reported?

Factor 3: Handoffs and transitions (four items)

- D3: Things 'fall between the cracks' when transferring patients from one unit to another (negatively worded).

- D5: Important patient care information is often lost during shift changes (negatively worded).

- D6: It is often unpleasant to work with staff from other hospital units (negatively worded).

- D7: Problems often occur in the exchange of information across hospital units (negatively worded).

\section{Factor 4: Non-punitive response to errors (three items)}

- A8: Staff feel like their mistakes are held (used) against them (negatively worded).

- A12: When an incident is reported, it feels like the person is being reported, not the problem (negatively worded).

- A16: Staff worry that mistakes they make are kept in their personnel file (negatively worded).

Factor 5: Teamwork across units (two items)

- D2: Hospital units do not coordinate well with each other (negatively worded).

D4: There is good cooperation among hospital units that need to work together.

Factor 6: Teamwork within units (three items)

- A1: People support one another in this unit.

- A3: When a lot of work needs to be done quickly, we work together as a team to get the work done.

- A4: In this unit, people treat each other with respect.

Factor 7: Communication openness (three items)

- C2: Staff will freely speak up if they see something that may negatively affect patient care.

- C4: Staff feel free to question the decisions or actions of those with more authority.

- C6: Staff are afraid to ask questions when something does not seem right (negatively worded).

\section{Factor 8: Management support for patient safety (two items)}

- D1: Hospital management provides a work climate that promotes patient safety.

- D8: The actions of hospital management show that patient safety is a top priority. speak up, if they see something that might negatively affect patient care.

Cox and Flin ${ }^{1}$ suggest that the nature of the safety climate is 'context-dependent'. Keiser ${ }^{84}$ argues that since safety climate measures include both general and contextualised items, excluding contextual measures might provide a rather deficient evaluation of the underlying safety climate construct. Thus, research currently supports the idea of integrating both qualitative and quantitative methods in developing a culturally appropriate instrument as standard approaches that exclusively rely on translation and quantitative validation may not be sufficient to produce an instrument that is applicable to the local context. ${ }^{75}$ As a result, the adopted tool will be able to reflect important safety climate themes that are specific to the local healthcare context.

A number of common dimensions were emerging rather consistently across international settings despite the lack of confirmation of the original factor structure of the HSOPSC in numerous studies. Those dimensions include: management support for patient safety, supervisors' action promoting patient safety, teamwork within and across units, handoffs and transitions, non-punitive response to error, frequency of incidents reported, communication openness and organisational learning.

The item composition of each factor of the optimal model of our study was compared with optimal models that were developed in Saudi Arabia, Palestine, England, the Netherlands, Turkey and Switzerland in addition to the original US HSOPSC questionnaire. ${ }^{60}$ This comparison is aimed at identifying a common set of patient safety climate items across different countries (see online supplementary appendix 6). The different adaptations of the HSOPSC did not confirm the original factor structure of the HSOPSC. ${ }^{60}$ Still, some dimensions corresponded to the ones proposed in the original HSOPSC model and items were repeated across the different studies. It should be noted that not all studies reported their optimum factor model structure. As a result, this created a difficulty in identifying the structure of the common dimensions across different countries.

\section{Strengths and limitations}

This is the first validation study of a standardised safety climate measure in a Kuwaiti healthcare setting. The study assessed the psychometric properties of the HSOPSC questionnaire and constructed an optimal model for assessing the patient safety climate in Kuwaiti hospitals. To examine the psychometric properties of the HSOPSC, a rigorous and scientific psychometric approach was designed and executed based on recommended reporting practices. Furthermore, strengths of both EFA and CFA analytical techniques were used to test the original HSOPSC model and construct an optimal model. Additionally, the researcher attempted to report all parameter estimates required for the reader to make valid interpretations of the results. Also, a large sample size $(n=1280)$ allowed for the data set to be split and 
for FA, including EFA and CFA, to be undertaken with acceptable model fit indices.

One limitation of this study is the number of items per factor in the optimal model. Three factors contained only two items per factor in the final eight-factor model. This is less than the recommended minimum of three items per factor. However, the items reported high loadings with strong theoretical sense. Also, similar findings were reported in the literature.

Another limitation is the exclusion of partially answered questionnaires. As a result, a subset of the total sample, with all items answered, was used for the validation of the psychometric properties of the HSOPSC. Data imputation techniques were avoided due to their potential impact on the tool's reliability and construct validity estimates and in order to minimise any possible biases. This led to a more uniform sample.

\section{CONCLUSION}

This is the first validation study of a patient safety climate questionnaire conducted in a Kuwaiti healthcare setting. The results clearly indicate the need for caution when using the original version of the HSOPSC questionnaire ${ }^{60}$ and highlight the importance of appropriate validation of safety climate surveys before applying them to different populations and healthcare contexts than those in which they were originally developed. The study also shows that the original composition of the HSOPSC dimensions was not confirmed in most studies. When compared with USA, the HSOPSC questionnaire may be assessing different dimensions of safety culture across different countries including Kuwait. ${ }^{60}$ More work is needed on cross-cultural investigations of differences in dimensionality to allow comparisons of healthcare safety climate results at an international level. ${ }^{28} 42$ This study provided comparative data on the use of the HSOPSC questionnaire internationally and nine common dimensions and items were identified when comparing the different studies that reported their optimum models. The optimal factor model that was constructed in this study can be used as a basis for measuring the patient safety climate in Kuwaiti hospitals and in evaluating changes in the safety climate over time as part of patient safety improvement initiatives.

Acknowledgements The authors thank every MOH staff member who took time to participate in this project despite their workload and endless commitments in order to contribute to a safer healthcare.

Contributors GA, PB and JM made considerable contributions to conception and design of the psychometric evaluation. GA completed the psychometric assessment and development of the final eight-factor model. GA was involved in drafting the manuscript while JM and PB have done revising of the drafts. All authors have given final approval of the version to be published and agreed to be accountable for all aspects of the work in ensuring that questions related to the accuracy or integrity of any part of the work are appropriately investigated and resolved. All authors read and approved the final manuscript.

Funding The authors have not declared a specific grant for this research from any funding agency in the public, commercial or not-for-profit sectors.

Competing interests None declared.

Patient consent for publication Not required.
Ethics approval Ethical approval was sought from the Medical, Veterinary and Life Sciences College ethics committee of the University of Glasgow in Scotland and the Medical and Health Sciences Research Committee of the Ministry of Health in Kuwait.

Provenance and peer review Not commissioned; externally peer reviewed.

Data sharing statement Data are available. Please contact the corresponding author.

Open access This is an open access article distributed in accordance with the Creative Commons Attribution Non Commercial (CC BY-NC 4.0) license, which permits others to distribute, remix, adapt, build upon this work non-commercially, and license their derivative works on different terms, provided the original work is properly cited, appropriate credit is given, any changes made indicated, and the use is non-commercial. See: http://creativecommons.org/licenses/by-nc/4.0/.

\section{REFERENCES}

1. Cox S, Flin R. Safety culture: Philosopher's stone or man of straw? Work Stress 1998;12:189-201.

2. Perrow C. A personal note on normal accidents. Organ Environ 2004;17:9-14.

3. Reason J. Combating omission errors through task analysis and good reminders. Qual Saf Health Care 2002;11:40-4.

4. Mearns KJ, Flin R. Assessing the state of organizational safetyculture or climate? Curr Psychol 1999;18:5-17.

5. Flin R, Burns $\mathrm{C}$, Mearns $\mathrm{K}$, et al. Measuring safety climate in health care. Qual Saf Health Care 2006;15:109-15.

6. Hellings J, Schrooten W, Klazinga N, et al. Challenging patient safety culture: survey results. Int J Health Care Qual Assur 2007;20:620-32.

7. Smits M, Groenewegen PP, Timmermans DR, et al. The nature and causes of unintended events reported at ten emergency departments. BMC Emerg Med 2009;9:16.

8. Blegen MA, Gearhart S, O'Brien R, et al. AHRQ's hospital survey on patient safety culture: psychometric analyses. J Patient Saf 2009;5:139-44.

9. Lee T, Harrison K. Assessing safety culture in nuclear power stations. Saf Sci 2000;34:61-97.

10. Colla JB, Bracken AC, Kinney LM, et al. Measuring patient safety climate: a review of surveys. Qual Saf Health Care 2005;14:364-6.

11. Singla AK, Kitch BT, Weissman JS, et al. Assessing patient safety culture: a review and synthesis of the measurement tools. Journal of Patient Safety 2006;2:105-15.

12. Fleming M. Patient safety culture measurement and improvement: a "how to" guide. Healthc Q 2005;8:14-19.

13. Jackson J, Sarac C, Flin R. Hospital safety climate surveys: measurement issues. Curr Opin Crit Care 2010;16:632-8.

14. Halligan M, Zecevic A. Safety culture in healthcare: a review of concepts, dimensions, measures and progress. BMJ Qual Saf 2011;20:338-43.

15. Pumar-Méndez MJ, Attree M, Wakefield A. Methodological aspects in the assessment of safety culture in the hospital setting: a review of the literature. Nurse Educ Today 2014;34:162-70.

16. Sammer CE, Lykens K, Singh KP, et al. What is patient safety culture? A review of the literature. J Nurs Scholarsh 2010;42:156-65.

17. Flin R. Measuring safety culture in healthcare: a case for accurate diagnosis. Saf Sci 2007;45:653-67.

18. Nieva VF, Sorra J. Safety culture assessment: a tool for improving patient safety in healthcare organizations. Qual Saf Health Care 2003;12(Suppl 2):17ii-23.

19. Alabdaly S. Alaan Newspaper. About the scandal of fatal errors in Adan Hospital, 2009.

20. Salama F. Alqabas newspaper. Medical errors kill a quarter of a million Americans a year, 2016.

21. Sami A. Aljarida newspaper. Medical errors, an obsession that worries everyone, 2015.

22. Sorra JS, Dyer N. Multilevel psychometric properties of the AHRQ hospital survey on patient safety culture. BMC Health Serv Res 2010;10:199.

23. Sorra J, Nieva V. Hospital Survey on Patient Safety Culture. AHRQ Publication No. 04-0041. Rockville, MD: Agency for Healthcare Research and Quality, 2004.

24. Alsalem G, Bowie P, Morrison J. Assessing safety climate in acute hospital settings: a systematic review of the adequacy of the psychometric properties of survey measurement tools. BMC Health Serv Res 2018;18:353.

25. Sorra J, Famolaro T, Dyer MN, et al. Hospital Survey on Patient Safety Culture: 2010 User Comparative Database Report. Rockville, MD, 2010. 
26. Human Factors and Ergonomics Society. Measuring hospital safety culture: Testing the HSOPSC scale, 2010.

27. Bodur S, Filiz E. Validity and reliability of Turkish version of "Hospital Survey on Patient Safety Culture" and perception of patient safety in public hospitals in Turkey. BMC Health Serv Res 2010;10:28.

28. Pfeiffer Y, Manser T. Development of the German version of the Hospital Survey on Patient Safety Culture: Dimensionality and psychometric properties. Saf Sci 2010;48:1452-62.

29. Perneger TV, Staines A, Kundig F. Internal consistency, factor structure and construct validity of the French version of the Hospital Survey on Patient Safety Culture. BMJ Qual Saf 2014;23:389-97.

30. Haugen AS, Søfteland E, Eide GE, et al. Patient safety in surgical environments: Cross-countries comparison of psychometric properties and results of the Norwegian version of the Hospital Survey on Patient Safety. BMC Health Serv Res 2010;10:10(1):1.

31. Smits M, Christiaans-Dingelhoff I, Wagner C, et al. The psychometric properties of the 'Hospital Survey on Patient Safety Culture' in Dutch hospitals. BMC Health Serv Res 2008;8:230.

32. Waterson P, Griffiths P, Stride C, et al. Psychometric properties of the Hospital Survey on Patient Safety Culture: findings from the UK. Qual Saf Health Care 2010;19:e2.

33. Agency for Healthcare Research and Quality. International Use of the Surveys on Patient Safety Culture Rockville, MD. 2015. http://www. ahrq.gov/professionals/quality-patient-safety/patientsafetyculture/ pscintusers.html (accessed 3 Feb 2016).

34. Gerrish K, Lacey A. The research process in nursing. Chichester: John Wiley \& Sons, 2010.

35. Sarantakos S. Social research: Palgrave Macmillan, 2012.

36. Tinsley HE, Tinsley DJ. Uses of factor analysis in counseling psychology research. J Couns Psychol 1987;34:414-24.

37. Tabachnick BG, Fidell LS. Using multivariate statistics. Boston, MA: Allyn \& Bacon, 2007

38. Cho YI, Johnson TP, Vangeest JB. Enhancing surveys of health care professionals: a meta-analysis of techniques to improve response. Eval Health Prof 2013;36:382-407.

39. McLeod CC, Klabunde CN, Willis GB, et al. Health care provider surveys in the United States, 2000-2010: a review. Eval Health Prof 2013;36:106-26.

40. Sorra J, Gray L, Streagle S. AHRQ Hospital Survey on Patient Safety Culture: User's Guide. Rockville, MD: Agency for Healthcare Research and Quality, 2016.

41. Allison PD. Missing data techniques for structural equation modeling $J$ Abnorm Psychol 2003;112:545-57.

42. Hutchinson A, Cooper KL, Dean JE, et al. Use of a safety climate questionnaire in UK health care: factor structure, reliability and usability. Qual Saf Health Care 2006;15:347-53.

43. Hill T, Lewicki P. Statistics: methods and applications: a comprehensive reference for science, industry, and data mining: StatSoft, Inc, 2006.

44. Gerbing DW, Hamilton JG. Viability of exploratory factor analysis as a precursor to confirmatory factor analysis. Structural Equation Modeling: A Multidisciplinary Journal 1996;3:62-72.

45. Henson RK, Roberts JK. Use of exploratory factor analysis in published research common errors and some comment on improved practice. Educational and Psychological measurement 2006;66:393-416.

46. Pett MA, Lackey NR, Sullivan JJ. Making sense of factor analysis: The use of factor analysis for instrument development in health care research. Thousand Oaks, CA: Sage Publications, 2003.

47. Kline RB. Principles and practice of structural equation modeling. New York: Guilford publications, 2015.

48. De Vellis RF, Dancer LS. Scale development: theory and applications. Journal of Educational Measurement 1991;31:79-82.

49. Field A. Discovering statistics using SPSS. London: Sage publications, 2009.

50. Suhr D. Reliability, exploratory \& confirmatory factor analysis for the scale of athletic priorities. Diambil pada tanggal 2003;2:274-28.

51. Kaiser HF. An index of factorial simplicity. Psychometrika 1974:39:31-6.

52. Hutcheson GD, Sofroniou N. The multivariate social scientist: Introductory statistics using generalized linear models: Sage, 1999.

53. Amos (Version 23.0) [Computer Program]. Chicago: SPSS, 2014.

54. Hu Li-tze, Bentler PM. Cutoff criteria for fit indexes in covariance structure analysis: Conventional criteria versus new alternatives. Structural Equation Modeling: A Multidisciplinary Journal 1999;6:1-55.

55. Ullman JB. Structural equation modeling: reviewing the basics and moving forward. J Pers Assess 2006;87:35-50.

56. Cattell RB. The Scree Test For The Number Of Factors. Multivariate Behav Res 1966;1:245-76.
57. Beavers AS, Lounsbury JW, Richards JK, et al. Practical considerations for using exploratory factor analysis in educational research. Practical assessment, research \& evaluation 2013;18:1-13.

58. Exploratory or confirmatory factor analysis? SAS Users Group International Conference. Cary: SAS Institute, Inc, 2006.

59. Kline P. An easy guide to factor analysis. London; Newyork, N.Y.: Routledge, 2014

60. Sorra J, Nieva V. Hospital Survey on Patient Safety Culture. Rockville, MD: Agency for Healthcare Research and Quality (AHRQ), 2004.

61. Alonazi MS. An evaluation of a patient safety culture tool in Saudi Arabia: The University of Sheffield, 2011.

62. Najjar S, Hamdan M, Baillien E, et al. The Arabic version of the hospital survey on patient safety culture: a psychometric evaluation in a Palestinian sample. BMC Health Serv Res 2013:13:1.

63. Al-Awa B, Al Mazrooa A, Rayes O, et al. Benchmarking the postaccreditation patient safety culture at King Abdulaziz University Hospital. Ann Saudi Med 2012;32:143-50.

64. Alahmadi HA. Assessment of patient safety culture in Saudi Arabian hospitals. Qual Saf Health Care 2010;19:e17-5.

65. El-Jardali F, Jaafar M, Dimassi H, et al. The current state of patient safety culture in Lebanese hospitals: a study at baseline. Int J Qual Health Care 2010;22:386-95.

66. El-Jardali F, Dimassi H, Jamal D, et al. Predictors and outcomes of patient safety culture in hospitals. BMC Health Serv Res 2011;11:11(1):1.

67. Al-Mandhari A, Al-Zakwani I, Al-Kindi M, et al. Patient safety culture assessment in oman. Oman Med J 2014;29:264-70.

68. Bahrami MA, Montazeralfaraj R, Chalak M, et al. Patient safety culture challenges: survey results of iranian educational hospitals. Middle East J Sci Res 2013;14:641-9.

69. El-Jardali F, Sheikh F, Garcia NA, et al. Patient safety culture in a large teaching hospital in Riyadh: baseline assessment, comparative analysis and opportunities for improvement. BMC Health Serv Res 2014;14:1): 1 .

70. Eiras M, Escoval A, Grillo IM, et al. The hospital survey on patient safety culture in Portuguese hospitals: instrument validity and reliability. Int J Health Care Qual Assur 2014;27:111-22.

71. LELd A, LOMd M, IGd S, et al. Adaptation and validation of the Hospital Survey on Patient Safety Culture in an electronic Brazilian version. Epidemiologia e Serviços de Saúde 2017;26:455-68.

72. Sarac C, Flin R, Mearns K, et al. Hospital survey on patient safety culture: psychometric analysis on a Scottish sample. BMJ Qual Saf 2011;20:842-8

73. Brborović H, Šklebar I, Brborović O, et al. Development of a Croatian version of the US Hospital Survey on Patient Safety Culture questionnaire: dimensionality and psychometric properties. Postgrad Med J 2014:90:125-32.

74. Haugen AS, Søfteland E, Eide GE, et al. Patient safety in surgical environments: cross-countries comparison of psychometric properties and results of the Norwegian version of the Hospital Survey on Patient Safety. BMC Health Serv Res 2010;10:279.

75. Zhu J, Li L, Zhao H, et al. Development of a patient safety climate survey for Chinese hospitals: cross-national adaptation and psychometric evaluation. BMJ Qual Saf 2014;23:847-56.

76. Reis CT, Laguardia J, Vasconcelos AG, et al. Reliability and validity of the Brazilian version of the Hospital Survey on Patient Safety Culture (HSOPSC): a pilot study. Cad Saude Publica 2016;32:e00115614

77. Robida A. Hospital survey on patient safety culture in slovenia: a psychometric evaluation. Int J Qual Health Care 2013;25:469-75.

78. Brajshori N, Behrens J. Translation, Cultural Adaption and Validation of Hospital Survey on Patient Safety Culture in Kosovo. Open J Nurs 2016;06:483-90.

79. Hedsköld M, Pukk-Härenstam K, Berg E, et al. Psychometric properties of the Hospital Survey on Patient Safety Culture, HSOPSC, applied on a large Swedish health care sample. BMC Health Serv Res 2013;13:332.

80. Ç Saraç. Safety climate in acute hospitals: University of Aberdeen, 2011.

81. Nie Y, Mao X, Cui H, et al. Hospital survey on patient safety culture in China. BMC Health Serv Res 2013;13:228.

82. Coyle IR, Sleeman SD, Adams N. Safety climate. J Safety Res 1995;26:247-54.

83. Ginsburg L, Gilin D, Tregunno D, et al. Advancing measurement of patient safety culture. Health Serv Res 2009;44:205-24.

84. Keiser NL. An Empirical Test of Context-Specific Safety Climate Measurement: A Comparison of Five Research Laboratory Safety Climate Measures to a General Measure of Safety Climate [Master's Thesis]: Texas A \& M University, 2015. 